\title{
Stress and Coping among the Parents of Children with Congenital Heart Disease: A Hospital Based Study
}

\section{Pratima Ghimire*}

Nepal Medical College, Jorpati, Kathmandu

\begin{abstract}
Introduction: Congenital heart defects are the most common, pervasive and serious chronic illness of all congenital malformations. The birth of a child can be stressful enough for many parents, turn into one of dashed joy and feeling of distress so there may be necessary for parents to obtain enough support from health professionals.

Methods: A descriptive Correlational study was conducted among 142 parents of children with Congenital Heart Disease attending Pediatric Medical Out Patient Department in Shahid Gangalal National Heart Center, Bansbari, Kathmandu. Data were collected using pre-tested structured interview schedule in Nepali version. The obtained data were analyzed by descriptive statistics (frequency, percentage, mean and standard deviation) and inferential statistics (chi-square and Karl Pearson's coefficient of correlation).

Results: The findings of the study revealed that near about three forth $(71.8 \%)$ of parents had moderately level of stress whereas $28.2 \%$ had low level of stress and $79.6 \%$ had moderately helpful level of coping and $20.4 \%$ had minimally helpful level of coping. There was negative correlation between stress and coping $(r=-0.076$ and $p$-value $=0.367)$ of parents. There were no any statistical association between socio-demographic characteristics of parents and stress level. Similarly, there were statistically significant association of level of coping with relationship with child, religion and occupation of parents ( $p$-value $0.004,0.002$ and 0.005 ) respectively.

Conclusion: The study concluded that with increased level of stress, there is decreased level of coping among the parents. Further, the findings suggest that health personnel must assess parenting stress at each visit to provide appropriate support and anticipatory guidance to families of children with Congenital Heart Disease.
\end{abstract}

Keywords: Stress; Coping; Parents; Children with congenital heart disease

\section{Introduction}

A new baby is the beginning of wonders, hopes and dreams and becoming parents is one of life's greatest blessings. A parent's dream of giving birth to the perfect child but the birth of a child with congenital heart disease challenges those dreams. This forces families to deal with a crisis for which they may be completely unprepared. Discovering one's child has a disability causes major stress, this can disrupt the total family functioning [1].

Congenital heart disease (CHD) is now estimated to be the second most prevalent chronic illness may have effects that pervasive consequence for family life. Recently, focused on resiliency variables, especially support and coping strategy, regulating the impact of stress. In the resiliency model of family stress, adjustment and adaptation, social support is viewed as one of the primary mediators between stress and well-being [2].

India has a large population with a perceived incidence of congenital heart disease in 8 per 1000 live births in children; nearly 180,000 kids are born yearly with this problem. Of these 60,000 to 90,0000 are critical and need early treatment. Nearly $10 \%$ of the infant mortality seen is due to congenital heart defects. As the number of centers capable of handling this is very few, a huge number of children are added to this pool each year of Congenital Heart Disease [3].

It can be a great burden for parents to be informed that their child is suffering from heart disease. The whole family might be affected and might undergo a stressful adjustment process, experiencing challenges such as attempting to understand the disease's effects, coping with uncertainty, and seeking reassurance from healthcare providers. Experiences such as somatization, depression, anxiety, distress, hopelessness, and social isolation can also arise. Mothers might also feel guilt and might wrongly blame themselves or they might feel frustration over not having a healthy baby. Those who have multiple children might additionally experience neglecting the healthy children [4].

Parents of children with heart disease were more likely than the normative population to report excessive parenting stress, especially related to characteristics of the child that make them difficult to parent. These parents expressed difficulty with setting limits or discipline of the child with heart disease. Parenting stress was related to the severity of the child's heart disease, family socioeconomic status, or time since most recent surgery. Clinicians must assess parenting stress at each health care visit to provide appropriate support and anticipatory guidance to families of children with heart disease [5].

The objectives of the present study were to find out the level of stress and coping, to determine the relationship between stress and coping among the parents of children with Congenital Heart Disease and to find out the association of level of stress and level of coping with selected socio demographic variables.

*Corresponding author: Pratima Ghimire, Nepal Medical College, Jorpati, Kathmandu, Tel: 09779849231817;E-mail: ppratima071@gmail.com

Received November 11, 2016; Accepted March 07, 2017; Published March 10 , 2017

Citation: Ghimire P (2017) Stress and Coping among the Parents of Children with Congenital Heart Disease: A Hospital Based Study. J Health Educ Res Dev 5: 212. doi: 10.4172/2380-5439.1000212

Copyright: (c) 2017 Ghimire P. This is an open-access article distributed under the terms of the Creative Commons Attribution License, which permits unrestricted use, distribution, and reproduction in any medium, provided the original author and source are credited. 


\section{Materials and Methods}

A descriptive Correlational study was conducted among 142 parents of children with Congenital Heart Disease attending Pediatric Medical Out Patient Department in Shahid Gangalal National Heart Center, (SGNHC) Bansbari, Kathmandu. Non-probability purposive sampling technique was adopted to select 142 parents as a sample for this study. Sample size was calculated at 95\% confidence level and 5\% confidence interval. The prevalence of children with Congenital Heart Disease (AVSD) being 10.3\% [6]. The Inclusion criteria for the sample were Parents of children with the age of 6 months - 15 years having Congenital Heart Disease, who were able to speak and understand Nepali and had stayed at least for 6 months with the child as a primary caregiver. A total of 142 parents were interviewed from dated $31^{\text {st }}$ January 2016 to $27^{\text {th }}$ February 2016 by using pretested structured interview schedule which was developed in consultation with eleven expertise in the related field. Data were collected after getting ethical clearance from Institutional Review Committee (IRC) National Medical College and Teaching Hospital, (NMCTH) Birgunj and IRC of SGNHC, Bansbari, Kathmandu. The collected data were organized and coded and entered in Epi.data 3.1 and export to IBM Statistical Package for Social Science (SPSS 20) version and appropriate statistical tests were performed to draw the inference

\section{Results}

The findings of the study revealed that majorities (54.2\%) of the parents were father, $43.0 \%$ were mother, and the least $(2.8 \%)$ were primary care-givers. Half of respondents (50\%) belonged to the range of 31-40 age groups. Similarly, 58\% were male and $41 \%$ female. More than half $(57 \%)$ of them were Hindu, followed by Buddhist $(26.8 \%)$ and others $(0.7 \%)$. Likewise, $23 \%$ of the respondents were educated up to secondary level, $18.3 \%$ were educated up to higher secondary and the least $3.5 \%$ were master and above. Near about one forth $(22.5 \%)$ parents were home-makers and 9.2\% were Governmental officers. More than half (54.9\%) were living in Urban whereas $16.2 \%$ were living in Semiurban. Half of the respondents (50.0\%) were from nuclear family and $3.5 \%$ were from extended family. Similarly, $54.9 \%$ had three members in family and $41.5 \%$ parents had a monthly family income of NRs. 5000-15,000 monthly.

Regarding the socio-demographic of child, $28.2 \%$ belonged to the age group of 3-6 years. More than half (57.7\%) were male and $42.3 \%$ were female. Among the number of siblings, $51.4 \%$ had two siblings. Likewise, the type of disease, 33.1\% had Atrial Septal defect and 57\% were diagnosed at the age of below 1 year. Similarly, numbers of hospitalization, $50.0 \%$ of the children were admitted 1-3 times.

Data presented in Table 1 depicts, area-wise stress among the parents, which shows that parents were having more physical stress with mean percentage score (45.25) followed by family and work stress with mean percentage score (35.8), psychological stress with mean percentage score (35.64) and financial stress with mean percentage score (26.66). Data presented in Table 2 reveals that near about three forth $(71.8 \%)$ of parents had moderately level of stress whereas $28.2 \%$ had low level of stress.
Data presented in Table 3 shows the area-wise coping score among the parents, which shows that parents were having more coping on understanding the health care situation through communication with other parents and consultation with the health care team with mean percent score (41.22) followed by maintaining social support, selfesteem and psychological stability with mean percent score (35.77) and family integration, cooperation and an optimistic definition of the situation with mean percent score (33.41).

Data presented in Table 4 reveals that $79.6 \%$ had moderately helpful level of coping and 20.4\% had minimally helpful level of coping among Parents of Children with Congenital Heart Disease.

Data presented in Table 5 illustrates that there is negative correlation between Stress and Coping among the parents of Children with Congenital Heart Disease with $r=-0.076$ and $p$-value $=0.367$ which was not statistically significant.

Data presented in Table 6, declaims that there was statistical positive correlation between financial stress and understanding health care situation as well as in family and work stress and total coping with $\mathrm{r}=0.189^{\star}$ and $\mathrm{r}=0.212^{\star}$ with $\mathrm{p}$-value 0.024 and 0.011 respectively. Likewise, there were statistical negative correlation between family and work stress and maintaining social support, selfesteem and psychological stability as well as in family and work stress and understanding health care situation with $\mathrm{r}=-0.210^{*}$ and $\mathrm{r}=-0.235^{* *}$ with p-value 0.012 and 0.005 respectively.

The study findings also revealed that there were no any statistical association between socio-demographic characteristics of parents and stress level. Similarly, there were statistically significant association of level of coping with relationship with child, religion and occupation of parents (p-value $0.004,0.002$ and 0.005 ) respectively.

\section{Discussion}

Regarding the socio-demographic characteristics of the parents of children with Congenital Heart Disease attending medical OPD of SGNHC revealed that $54.2 \%$ were father, $43.0 \%$ were mother and only $2.8 \%$ were primary care givers whose aged ranged from 31-40 years. More than half $58 \%$ were male and $41 \%$ female. Similarly, $57 \%$ of them were Hindu, followed by Buddhist (26.8\%) and others $(0.7 \%)$. Likewise, $23 \%$ of the parents were educated up to secondary level, $18.3 \%$ were educated up to higher secondary and the least $3.5 \%$ were master and above. Near about one forth (22.5\%) parents were homemakers and 9.2\% were Governmental officers. More than half (54.9\%) were living in Urban whereas $16.2 \%$ were living in Semi-urban. Half of the respondents $(50.0 \%)$ were nuclear family and $3.5 \%$ were extended family. Similarly, $54.9 \%$ had three members in the family.

Regarding the socio-demographic of child information, $28.2 \%$ belonged to the age group of 3-6 years. More than half (57.7\%) were male and $42.3 \%$ were female. Among the number of siblings, $51.4 \%$ had two siblings. Likewise, the type of disease, $33.1 \%$ had Atrial Septal defect and $57 \%$ were diagnosed at the age of below 1 year. Similarly regarding the numbers of hospitalization, $50.0 \%$ of the children were admitted 1-3 times.

\begin{tabular}{|c|c|c|c|}
\hline Sub-scales & Mean Score \pm SD & Percentage of mean Score & Range \\
\hline Physical stress & $9.05 \pm 1.55$ & 45.25 & $4-13$ \\
\hline Psychological stress & $16.04 \pm 3.89$ & 35.64 & $9-31$ \\
\hline Family and work stress & $12.53 \pm 3.69$ & 35.8 & $4-22$ \\
\hline Financial stress & $4.19 \pm 1.58$ & 26.66 & 35 \\
\hline
\end{tabular}

Table 1: Stress score according to sub-scales among parents of children with congenital heart disease $(n=142)$. 
Citation: Ghimire P (2017) Stress and Coping among the Parents of Children with Congenital Heart Disease: A Hospital Based Study. J Health Educ Res Dev 5: 212. doi: 10.4172/2380-5439.1000212

Page 3 of 4

\begin{tabular}{|c|c|c|}
\hline Level of stress & Frequency & Percentage \\
\hline Moderate stress & 102 & 71.8 \\
\hline Low stress & 40 & 28.2 \\
\hline
\end{tabular}

Table 2: Level of stress score among parents of children with congenital heart disease. $n=142$.

\begin{tabular}{|c|c|c|c|c|}
\hline Area-wise Sub-scale & Mean score \pm SD & Percent of mean Score & Range & $\begin{array}{l}\text { Maximum possible } \\
\text { score }\end{array}$ \\
\hline $\begin{array}{c}\text { Family Integration, Cooperation and an Optimistic Definition } \\
\text { of the Situation }\end{array}$ & $26.73 \pm 3.13$ & 33.41 & $21-40$ & 80 \\
\hline $\begin{array}{l}\text { Maintaining Social Support, Self -esteem and Psychological } \\
\text { Stability }\end{array}$ & $35.77 \pm 3.32$ & 35.77 & $29-44$ & 100 \\
\hline $\begin{array}{c}\text { Understanding the Health Care Situation through } \\
\text { Communication with other Parents and Consultation with } \\
\text { the Health Care Team }\end{array}$ & $18.55 \pm 1.86$ & 41.22 & $13-24$ & 45 \\
\hline
\end{tabular}

Table 3: Coping score according to sub-scale among parents of children with congenital heart disease. $n=142$.

\begin{tabular}{|c|c|c|}
\hline Level of Coping & Frequency & Percentage \\
\hline Minimally helpful & 29 & 20.4 \\
\hline Moderately helpful & 113 & 79.6 \\
\hline
\end{tabular}

Table 4: Level of Coping among parents of children with congenital heart disease. $n=142$.

\begin{tabular}{|c|c|c|c|}
\hline Characteristics & Mean score \pm SD & Correlation & p-value \\
\hline Stress & $41.83 \pm 7.15$ & -0.076 & 0.367 \\
\hline Coping & $81.07 \pm 7.16$ & & \\
\hline
\end{tabular}

Table 5: Correlation between stress and coping score among the parents of children with congenital heart disease. $n=142$.

\begin{tabular}{|c|c|c|c|c|c|}
\hline Soping & Physical stress & Psychological stress & Family and work stress & Financial stress & Total stress \\
\hline $\begin{array}{l}\text { Family Integration, Cooperation and an } \\
\text { Optimistic Definition of the Situation }\end{array}$ & $\begin{array}{l}0.057 \\
(0.501)\end{array}$ & $\begin{array}{l}0.051 \\
(0.548)\end{array}$ & $\begin{array}{l}-0.122 \\
(0.148)\end{array}$ & $\begin{array}{l}-0.011 \\
(0.896)\end{array}$ & $\begin{array}{l}-0.025 \\
(0.764)\end{array}$ \\
\hline $\begin{array}{c}\text { Maintaining Social Support, Self -esteem and } \\
\text { Psychological Stability }\end{array}$ & $\begin{array}{l}-0.0017 \\
(0.843)\end{array}$ & $\begin{array}{c}0.028 \\
(0.740)\end{array}$ & $\begin{array}{l}-0.210^{*} \\
(0.012)\end{array}$ & $\begin{array}{c}0.143 \\
(0.089)\end{array}$ & $\begin{array}{l}-0.065 \\
(0.440)\end{array}$ \\
\hline $\begin{array}{l}\text { Understanding the Health Care Situation } \\
\text { through Communication with other Parents } \\
\text { and Consultation with the Health care Team }\end{array}$ & $\begin{array}{c}-0.067 \\
(0.426)\end{array}$ & $\begin{array}{l}-0.073 \\
(0.390)\end{array}$ & $\begin{array}{c}-0.235^{* *} \\
(0.005)\end{array}$ & $\begin{array}{c}0.189^{*} \\
(0.024)\end{array}$ & $\begin{array}{c}-0.134 \\
(0.112)\end{array}$ \\
\hline Total coping & $\begin{array}{c}0.000 \\
(0.997)\end{array}$ & $\begin{array}{l}0.016 \\
(0.846)\end{array}$ & $\begin{array}{l}0.212^{*} \\
(0.011)\end{array}$ & $\begin{array}{c}0.111 \\
(0.189)\end{array}$ & $\begin{array}{l}-0.076 \\
(0.367)\end{array}$ \\
\hline
\end{tabular}

*Statistically Significant at the level of $(p=0.05) ;{ }^{*}$ Statistically Significant at the level of $(p=0.01)$

Table 6: Correlation between sub-scales of stress and coping among the parents of children with congenital heart disease. $n=142$.

Regarding level of stress, result revealed that majority of parents (71.8\%) had moderate stress and $28.2 \%$ parents had low stress. This finding was supported by the study findings of Katherine, which showed moderate $(58.3 \%)$, followed by high (25\%) and low $(16.7 \%)$ level of stress in parents of children with Congenital Heart Disease.

Regarding the level of coping, majority (79.6\%) had moderately helpful level of coping and $20.4 \%$ had minimally helpful level of coping among parents of children with Congenital heart disease. Findings of the study is supported by the study conducted by Sullivan and Kathryn [7], which reported coping strategies related to maintaining family integration and an optimistic definition were significantly associated with spirituality. By being able to recognize factors associated with parental coping the medical and social support community able to better facilitate positive coping mechanisms for parents of children with $\mathrm{CHD}$ which was concluded that there was moderately helpful of the coping patterns.

Regarding the correlation between stress and coping, there were negative correlation between stress and coping with $\mathrm{r}=-0.076$ and $\mathrm{p}$-value $=0.367$. The findings of the study were supported by the study findings of Katherine Jo Greshik [8-19] which reported negative correlation between stresses and coping.

\section{Conclusion}

On the basis of findings, it can be concluded that there was moderate level of stress and moderately helpful of coping pattern among the parents of children with Congenital Heart Disease and negative correlation between stress and coping. There were no association between stress and socio-demographic characteristics of parents and there was only significant association between coping and relation with child, religion and occupation of the parents. So, it is recommended that the health professionals must assess the parenting stress at each follow up to promote appropriate support, guidance and counseling to the parents of children with Congenital Heart Disease.

\section{References}

1. Margaret M (2008) A Descriptive Study to Assess the Level of Stress and its Association with the Quality of Life of Parents having Children with Major Congenital Anomalies. Indira Gandhi Institute of Child Health, Bangalore.

2. Tak YR, McCubbin M (2002) Family stress, perceived social support and 
Citation: Ghimire P (2017) Stress and Coping among the Parents of Children with Congenital Heart Disease: A Hospital Based Study. J Health Educ Res Dev 5: 212. doi: 10.4172/2380-5439.1000212

Page 4 of 4

coping following the diagnosis of a child's congenital heart disease. Journal of advanced nursing 39: 190-198.

3. Saxena A (2007) Consensus on Timing of Intervention for Common Congenital Heart Disease. Journal of Indian Pediatric 45: 117-126.

4. Bruce E, Lilja C, Sundin K (2014) Mothers' lived experiences of support when living with young children with congenital heart defects. Journal for specialists in pediatric nursing 19: 54-67.

5. Uzark K, Jones K (2003) Parenting Stress and Children with Heart Disease. Journal of Pediatric Health Care 17: 163-168.

6. Kapoor R, Gupta S (2008) Prevalence of Congenital Heart Disease of Kanpur India. Indian Pediatric 45: 309-311.

7. Katherine JG (1999) Stress and Coping of Parents of Pediatric Heart Transplant Patients and Parents of Pediatric Patients with Chronic Heart Disease: A Comparative Study Implications for Health Care Providers, USA.

8. Sullivan L, Kathryn J (2011) Coping Patterns among Parents of Children with Congenital Heart Disease.

9. Jackson AC, Frydenberg E, Liang RP, Higgins RO, Murphy BM (2015) Familial impact and coping with child heart disease: a systematic review. Pediatric cardiology. 36: 695-712.

10. Bahadur KC, Sharma D, Shrestha MP, Gurung S, Rajbhandari S, et al. (2002) Prevalence of Rheumatic and Congenital Heart Disease in School Children of Kathmandu Valley in Nepal. Indian Heart Journal 55: 615-618.

11. Lee S, Yoo J, Yoo Y (2007) Parenting Stress in Mothers of Children with Congenital Heart Disease. Asian Nursing Research 1: 116-124.
12. Marelli AJ, Ionescu-lttu R, Mackie SS, Guo L, Dendukuri N, et al. (2014) Lifetime Prevalence of Congenital Heart Disease in the General Population from 2000 to 2010. Journal of American Heart Association 130: 749-756.

13. Sadowski SL (2009) Congenital cardiac disease in the newborn infant: past present, and future. Critical care nursing clinics of North America 21: 37-48.

14. Saied H (2006) Stress, Coping, Social Support and Adjustment among Families of CHD Children in PICU After Heart Surgery. Case Western Reserve University, Ohio.

15. Shah GS, Singh MK, Pandey TR, Kalakheti BK, Bhandari GP (2008) Incidence of congenital heart disease in tertiary care hospital. Kathmandu University Medical Journal 6: 33-36.

16. Soulvie MA, Desai PP, White CP, Sullivan BN (2012) Psychological distress experienced by parents of young children with congenital heart defects: A comprehensive review of literature. Journal of Social Service Research 38: 484-502.

17. Yildiz A, Celebioglu A, Olgun $H$ (2009) Distress levels in Turkish parents of children with congenital heart disease. Australian Journal of Advanced Nursing 26: 39-46.

18. Bajracharya S, Shrestha A (2016) Parental coping mechanisms in children with congenital heart disease at tertiary cardiac centre. Asian Journal of Medical Sciences 7: 75-79.

19. Basnet NB (2006) Congenital Heart Disease in Nepalese Children. Journal of Nepal Medical Association 45: 281-282. 